\title{
The mediating effect of knowledge of inventory management in the relationship between inventory management practices and performance: The case of micro retailing enterprises
}

\author{
Kamilah Ahmad \\ Shafie Mohamed Zabri \\ University Tun Hussein Onn Malaysia, Malaysia
}

\begin{abstract}
Keywords
Inventory management, performance, knowledge of owner/manager, retailing sector, small and medium enterprises
\end{abstract}

\begin{abstract}
The adoption of systematic inventory management practices (IMPS) is a critical success factor for businesses in a retailing industry. Nevertheless, there is lack of thorough understanding in the field of inventory management within a micro business setting. Thus, this study empirically explores the extent of IMPs in the micro retailing enterprises and the mediating effect of knowledge of IMPs in the relationship between IMPs and micro enterprises' performance. A questionnaire was sent to a random sample of 300 Malaysian owners/managers of micro retailing enterprises and 100 completed replies were received. The study finds that the usage level of systematic IMPs is moderate among the micro retailing enterprises with evaluation of suppliers as the most frequently applied IMPs. Meanwhile, inventory management activities related to reorder point, purchasing and controlling are adopted moderately. Interestingly, this study confirms that there is a significant direct effect of IMPs on enterprise performance. The relationship is partially mediated by knowledge of inventory management. This research enhances the body of knowledge in inventory management and the firm's performance particularly within the context of micro enterprises.
\end{abstract}

Corresponding author: Kamilah Ahmad

Email addresses for corresponding author: kamilah@uthm.edu.my

First submission received: 17th May 2017

Revised submission received: 3rd August 2017

Accepted: 8th September 2017

\section{Introduction}

Inventory management is among key functions in a business operation particularly in meeting high customer's demand (Baron et al., 2010). This function requires a balance between fulfilling the demands of customers and keeping sufficient supply of merchandises (Heizer and Render, 2014, p. 512). Ultimately, its fundamental aim is to turn over inventory as quickly as possible without losing sales (Gitmann and Zutter, 2012). Among the major advantages of systematic inventory management are to reduce costs related to inventory holding, stock-out costs as well as purchasing costs by buying in quantity and speculate on price movements (Jonsson and Mattsson, 2008; Koumanakos, 2008; Basu and Wang, 2011). Inventory management also helps to improve firm's production scheduling, production and delivery lead times (Jonsson and Mattsson, 2008) and ultimately increases the overall firm performance (Koumanakos, 2008). Trade-off decisions between costs and the level of required sales target often produces a complex decision making. De Vries (2011) argued that finding a proper balance between quality of services and costs is challenging as it generates pressures on many other aspects of production activities (Pong and Mitchell, 2012). Organisations should be able to recognise how to maintain sufficient stocks for continuous production to meet customer's demand as well as to avoid losses as a result of running out of stockpiles. In this case, the knowledge of inventory management among owners/managers and staff is crucial to handle issues in inventory management.

In a micro enterprise context, there is a limited use of systematic IMPs due to the lack of resources. Today's financial pressures force small enterprises to reduce their inventories, which led to inventory stock-outs (Chikan and Whybark, 1990). This is because much of a firm's costs were invested in 
inventory holding, transportation and management costs (Waller et al., 2006). Furthermore, small enterprises also face issues on low attention on forecasting of inventory, training and development of employees (Rajeev, 2008) and unwillingness to share information related to inventory management within the micro retailing enterprises (Ahmad and Mohamed Zabri, 2016) which eventually reduce the overall competitiveness of enterprises in this sector.

There are substantial empirical evidences concerning the inventory management practices and its relationship with performance (Capkun et al., 2008; Boute et al., 2006; Koumanakos, 2008; Kolias et al., 2010; Ogbo et al., 2014; and Panigrahi, 2014). Despite robust information on IMPs and performance in the literature, empirical evidence is lacking on this relationship within the micro retailing sector. Retailing is a process of selling consumer goods or services to customers through multiple channels of distribution to earn profits. An intense global competition and increased inventory carrying costs have motivated today's retailers for speeding up inventory turnover to maintain their survival. Prior studies suggest that IMPs is a critical success factor for retailing industry as Bala (2012) demonstrated that retailers with sophisticated systems for better demand forecasting and improved inventory management had an edge over the others in terms of profitability. This is due to the accuracy of information received from such system which enabling a more efficient business decision. Thus, it is worthwhile to investigate this sector for further understanding of the nature of their IMPs.

Based on the significant literature gap, the study addresses this issue by examining the effect of IMPs on micro retailing enterprises performance and how the knowledge of IMPs mediates the relationship between the extent of IMPs and performance. Obtaining further evidence regarding this issue may help in understanding the dynamics of inventory-performance relationship as SMEs have not only some unique characteristics that differentiate them from larger firms, but also a higher failure rate as compared to the larger firms (Elsayed and Wahba, 2016). Furthermore, the existing evidence regarding inventory-performance relationship is still inconclusive (Elsayed and Wahba, 2016). Thus, this study rectifies the deficiency by providing evidence on IMPs in the micro retailing sector and a further investigation through the incorporation of knowledge of IMPs as the mediating variable on IMPsperformance link. The rest of this paper is set out as follows; the literature review is discussed in the next section followed by methodology, results discussions and conclusion.

\section{Literature review and hypothesis development \\ 2.1 Inventory management and performance}

Past research in inventory management and performance reveal that there is a significant relationship between IMPs and performance (Deloof, 2003; Koumanakos, 2008; Shah and Shin, 2007; Jonsson and Mattsson, 2008; and Capkun et al., 2009). For example, Deloof (2003) revealed significant and negative relation between gross operating income and the number of inventory days based on a sample of non-financial Belgian firms. The results proposed that managers could create value for their shareholders by reducing the number of inventory days to a reasonable minimum. Boute et al. (2006) who analysed inventory turnover in Belgium's manufacturing sector and the impact of reducing inventory on financial performance, found that companies with the highest inventory ratio had a higher chance of bad financial performance. The study asserted that firms with high inventory ratios were most likely to be weak financial performers. Similarly, Fullerton et al. (2003) and Demeter (2003) revealed that high inventory turnover associated significantly with a higher return on sales. Studies by Chen et al. (2005) and Chen et al. (2007) concluded that high inventory levels were associated with poor long-term stock returns. Next, Koumanakos (2008) indicated that the higher the level of inventory, the lower its rate of returns. Likewise, Kolias et al. (2011) found that inventory turnover ratio was negatively correlated with gross margin.

In a further study, Garcia-Teruel and Martinez-Solano (2007) demonstrated that managers could create value by reducing their inventories and the number of days for which their accounts were outstanding. Likewise, Shah and Shin (2007) revealed that inventory reduction had a direct and significant effect on performance. Panigrahi (2013) indicated that inventory conversion period had an inverse relationship with the firms' profitability i.e., when the inventory conversion period (ICP) days increases, the profitability of the firm decreases, and vice versa. Next, Elsayed and Wahba (2016) found that while inventory to sales ratio affected organisation's performance negatively in the initial growth stage and the 
maturity stage, it exerted a positive and significant coefficient on performance in either the rapid growth stage or the revival stage. Jonsson and Mattsson (2008) concluded that the way of determining and the review frequency of safety stocks and lead times had great importance for the planning performance of MRP methods, while the determination and review of order points, review frequencies and run-out times were important for re-order point methods. Capkun et al. (2009) investigated the relationship between inventory performance and financial performance in the US manufacturing sector based on financial information gathered from 1980 to 2005. The study found that there was a significant positive correlation between inventory performance and measures of financial performance. Gaur and Kesavan (2009) found that there was a strong relation between inventory turnovers, firm's size and increased in sales. Similarly, Pong and Mitchell (2012) indicated a positive association between increased in profit return and improvement in inventory days using a sample of the UK firms. The performance of inventory management may be contributed by size of a firm. Gaur and Kesavan (2009) noted that firm size may affect a firm's capability to achieve increased competitiveness and financial performance. Their study demonstrated that the increase in inventory turnover and sales performance is depending upon the firm size. This is because larger firms are more likely to have a bigger market share and control over the competitive market. Furthermore, larger firms have more access to resources compared to a smaller business unit.

Despite numerous significant evidences in the relationship between IMPs and the firm's performance, there is little evidence that reveal contradicting results. For example, Vastag and Whybark (2005) demonstrated that there was no relationship between inventory turnover and performance. Likewise, Cannon (2008) found that there was no correlation between inventory management efficiency and overall financial performance. When the effects of time were taken into account, turnover improvement on average had a slightly negative effect on return on asset. Keramidou et al. (2012) investigated the relationship between efficiency and profitability revealed that the results did not confirm a positive strong correlation between efficiency and profitability. Companies that had the capability of producing their products with the best practices were not always capable of generating the maximum profits. Similarly, Obermaier and Donhauser (2012) demonstrated that organisations that had the lowest (highest) inventory level had also the worst (best) performance level. They concluded that moving towards zero-inventory case was not always recommended. Folinas and Shen (2014) found that there was no significant correlation between inventory turnover and financial performance. Overall, empirical evidences on IMPs and performance relationship produce mixed results. Thus, the following hypothesis is suggested:

$H_{1}$ : Inventory management practices have significant relationship with enterprise performance.

\subsection{Inventory management practices and knowledge of IMPs}

Previous studies contend that qualified personnel with sufficient knowledge of inventory management should be considered in running IMPs. One of the critical barriers to inventory management adoption is the inadequacy of qualified personnel, who have little knowledge on how to handle inventory management effectively. Water (2003) proposed that organisations should provide sufficient training to key employees in understanding the inventory control system. Ogbo et al. (2014) argued that management's capability could be acquired with a good knowledge in such functions. Furthermore, the culture of good practices in inventory management would distribute knowledge among the staff through training and information sharing. Thus, it is crucial for any organisations to acquire expertise and knowledge for better inventory management practices. Thus, this study proposes the following hypothesis.

$\mathrm{H}_{2}$ : Inventory management practices have significant relationship with inventory management knowledge.

\subsection{Knowledge of IMPs and performance}

In the SMEs context, one common issue that may limit the adoption of systematic practice is the abilities of qualified human resources. Prior studies highlight that qualified human factor is important for the adoption of sophisticated management practices (Ahmad and Mohamed Zabri, 2015), thus it may increase firm performance. Expertise and knowledge are the management skills that any organisation should acquire (Ogbo et al., 2014). Kotzab and Teller (2005) argued that the lack of qualified personnel 
and knowledge regarding the demand and the inaccuracy of virtual and real stock in the stores caused inefficiency in inventory management. A study by Ayad (2008) found that different stores within the same companies and different departments within the same stores delivered different results, mainly due to human factors, specifically in terms of critical thinking, functional knowledge and leadership. In every planning and control situation there were different planning conditions that impact the possibility of favourable application modes, but which might also have a direct impact on planning performance. Such conditions included the educational and knowledge level, management commitment and the organisational design and function of planning and control (Jonsson and Mattsson, 2008). Strohhecker and Grobler (2013) suggested that appropriate knowledge was critical in implementing systematic IMPs. Thus, we suggest that the presence of knowledgeable staff or owners/managers is associated with a better adoption of IMPs.

$H_{3:} \quad$ Inventory management knowledge has significant relationship with enterprise performance.

\subsection{The mediating role of knowledge of IMPS in relationship between IMPs and performance.}

The literature suggests that inventory management has a significant link with performance and the important role of knowledge and competent human factor in assisting the running of IMPs towards enhancing performance. The allocation of tasks, the decision-making processes, the behaviour of the personnel involved in the inventory system, as well as communication processes appear to be important contextual factors when analysing and redesigning inventory systems (De Vries, 2011). Ahmad and Mohamed Zabri (2016) demonstrated that knowledge and adequate training in managerial practices initiated the adoption of systematic managerial practices for achieving higher performance level. In the IMPs context, Kotzab and Teller (2005) argued that the lack of knowledge in managing stock led to poor inventory management and ultimately to poor performance. Similarly, Bahri et al. (2011) revealed that training for employees to gain adequate inventory management knowledge could improve management's quality and therefore influenced the value of inventory performance. In this case, we propose that the knowledge of IMPs has a mediating role in the relationship between IMPs and performance. Thus, the fourth hypothesis is stated as follows:

$H_{4:} \quad$ Inventory management knowledge mediates the relationship between inventory management practices and enterprise performance.

Figure 1 presents the conceptual model that shows the role of inventory management knowledge as a mediator in relationship between IMPs and performance.

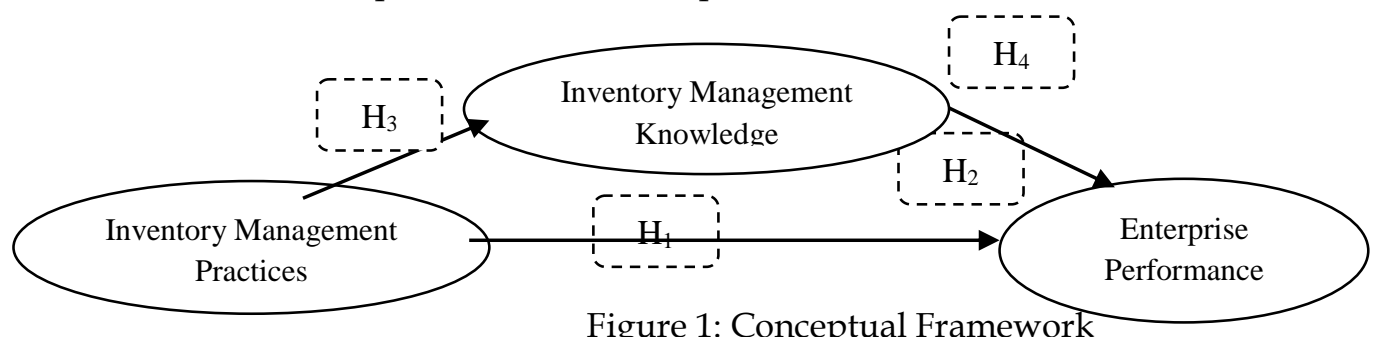

The following section discusses the methodology in more detail.

\section{Methodology}

This study utilises structural equation modelling (SEM) in testing the hypotheses. Basically, SEM consists of two components; the measurement model, which reduces observed variables to a smaller number of latent factors; and the structural equation model, which defines causal relationships among these latent factors.

\subsection{Sample}

This study focuses on micro retailing enterprises as this sector is one of the significant sectors in Malaysia. In Malaysia, micro enterprises are businesses that fall within the criteria of having either an annual sales turnover of less than RM300,000 (equivalent to approximately USD75,000) or fewer than five employees. As this sector comprises a significant number of the Malaysian SMEs, this sector promotes the growth of retailing activities in Malaysia. According to SMECorp (2016) the SMEs activities are mostly 
from the wholesale and retail industries. As such it is worthwhile to examine IMPs from the context of the micro enterprise sector.

Most of the items developed in this study were adapted from a study by Ahmad and Mohamed Zabri (2016). IMPs and enterprise performance were evaluated based on the subjective measures which is more suitable in a small business context when objective performance and IMPs data are unavailable. Pretest and pilot tests were conducted to enhance the validity and reliability of the data and a few amendments were made based on the suggestions. The questionnaires were distributed directly to a sample of 300 owners/managers of micro retailing enterprises. After several follow-ups, a total of 100 completed responses were received which equals to $33.33 \%$ of the response rate. The degree of use of IMPs were measured by using 24 items (Inv1 to Inv24) based on 7-point Likert scale where 1= Very Rarely and 7= Very Frequent. Meanwhile knowledge of IMPs (three items: Know1 to Know3) and Performance (five items: inventory turnover, profit margin, sales growth, delivery on-time, customers satisfaction and customer complaints) were measured using 7 point Likert scales where 1= Very Low and 7= Very High. The reliability analysis indicated that the Cronbach's alpha values were greater than 0.8 which suggests that all items used as variables in this study were found to be highly reliable.

\subsection{Factor analysis}

Principal components analysis (PCA) with varimax rotation on 24 IMPs items was first carried out using SPSS to confirm the main dimensions of inventory management. Due to low factor loadings which below than 0.6 , eight items had to be removed. The final PCA analysis as shown in Table 1 indicates that the factor loadings in the measurement model were all greater than 0.60, leading to a conclusion that the reliabilities of individual items are within the acceptable level. The 16 items of IMPs were divided into three broad dimensions. The first category with four items (Inv1- Inv4) was categorised as inventory reorder activities. The second category consisted of eight items (Inv5, Inv6, Inv7, Inv8, Inv10, Inv11, Inv12, Inv13) was classified as inventory control activities and the third group (Inv17 to Inv23) was categorised as supplier monitoring activities.

Table 1: Factor Analysis Pattern Matrix

\begin{tabular}{clccc}
\hline & & \multicolumn{3}{c}{ Factor } \\
& & 1 & 2 & 3 \\
\hline 1 & Inv1 & & & .992 \\
2 & Inv2 & & & .800 \\
3 & Inv3 & & & .683 \\
4 & Inv4 & & & .764 \\
5 & Inv5 & .873 & & \\
6 & Inv 6 & .850 & & \\
7 & Inv 7 & .956 & & \\
8 & Inv 8 & .672 & & \\
9 & Inv 10 & .739 & & \\
10 & Inv 11 & .905 & & \\
11 & Inv 12 & .911 & & \\
12 & Inv 13 & .729 & & \\
13 & Inv 17 & & .624 & \\
14 & Inv 21 & & .934 & \\
15 & Inv 22 & & .918 & \\
16 & Inv 23 & & .690 & \\
\hline
\end{tabular}

a. Rotation converged in 5 iterations. 
Normality assessment was made by evaluating the measure of skewness of each item. The absolute values of skewness for all independent and dependent variables were less than 1.5, which suggested that all the items were normally distributed.

\section{Results and discussions}

This section discusses the results of the data collected from 100 respondents using the descriptive analysis and structural equation model. The next section discusses the background of the responding enterprises.

\subsection{Profile of the responding enterprises}

Table 2 shows the characteristics of the sample in terms of the number of employees, average annual sales, duration in business and inventory management techniques, which provides the overview of the respondents' profiles. About two-thirds of the responding enterprises are proprietors and have been in business for less than three years. Furthermore, the results show that half of the respondents have diploma and bachelor degree certificates. In terms of inventory management techniques, the rule of thumb is the most frequent inventory management techniques used by micro retailing enterprises. EOQ, bar code tagging and VMI are only applied by a small number of respondents.

Table 2: Profile of the responding enterprises

\begin{tabular}{clccc}
\hline No. & Items & $\%$ & Items & $\%$ \\
\hline 1 & Business duration & & 2 & Education level \\
& Less than 3 years & 66 & UPSR/PMR & 4 \\
& 4-5 Years & 12 & SPM & 37 \\
& 6-7 Years & 13 & STPM & 9 \\
& 8-9 Years & 3 & DIPLOMA & 19 \\
& More than 10 Years & 6 & Bachelor Degree & 31 \\
& Total & 100 & Total & 100 \\
3 & & 4 & Inventory techniques used & 15.5 \\
& Business form & 64 & Economic Order Quantity (EOQ) & 32.2 \\
& Proprietorship & 9 & Other techniques & 9.5 \\
& Partnership & 27 & Vendor managed inventory & 7.1 \\
& Companies & 100 & Bar coding tagging & 35.7 \\
& Total & & Rule of Thumb &
\end{tabular}

\subsection{Details on information of inventory management practices}

This section discusses in detail the current state of IMPs which were measured using a 16-item scale related to IMPs under three main components (Reorder point: 4 items, Inventory control: 8 items and Supplier monitoring: 4 items). Supplier monitoring activities are the most frequent IMPs adopted by micro retailing enterprises with an average mean score of 5.30. This is followed by inventory control and inventory reorder activity with average mean values of 4.89 and 4.81 , respectively. The overall IMPs can be considered at a good level as its average mean score is 5.00 .

Table 3: Descriptive Statistics

\begin{tabular}{lcccc}
\hline & Minimum & Maximum & Mean & $\begin{array}{c}\text { Std. } \\
\text { Deviation }\end{array}$ \\
\hline Reorder Point & 1 & 7 & 4.81 & 1.062 \\
Inventory Control & 1 & 7 & 4.89 & 1.459 \\
Supplier & 2 & 7 & 5.30 & 1.332 \\
IMPs & 1 & 6 & 5.00 & 1.065 \\
\hline
\end{tabular}

\subsection{Correlation tests}

This section provides the results of correlation analysis between enterprises characteristics and IMPs and performance. Table 4 shows that all inventory management subcomponents have significant, strong and positive relationships with performance. The study also reveals that there is a strong and significant relationship between IMPs and performance with the correlation value of 0.637 . Thus, the test implies that micro enterprise with a higher level of IMPs is more likely to have a better performance. The findings demonstrate that the size of enterprises which is represented by either the number of employees and average annual sales has a significant and positive relationship with IMPs. This suggests that larger 
enterprises are more likely to implement systematic IMPs as compared to smaller enterprises and have more consistency in profitability level. This is due to the fact that larger firms have sufficient resources to successfully implement high profile management initiatives (Pong and Mitchell, 2012). Kinney and Wempe (2002) argued that inventory control was superior in larger firms. In addition, Gaur and Kesavan (2009) claimed that the firm's size might affect a firm's capability to achieve increased competitiveness and financial performance. This is shown in a study by Panigrahi (2013) who found that profitability improves with an increase in the firm's size.

Table 4: Correlation analysis between size, IMPs and performance

\begin{tabular}{|c|c|c|c|c|c|c|c|}
\hline & Employee & Annual Sales & Reorder Point & Inventory Control & Supplier & IMPs & Performance \\
\hline \multirow[t]{2}{*}{ Employee } & 1 & $.505^{\star *}$ & $.418^{* *}$ & $.279^{* \star}$ & 0.152 & $.330^{* *}$ & 0.186 \\
\hline & & 0 & 0 & 0.005 & 0.131 & 0.001 & 0.063 \\
\hline \multirow{2}{*}{\multicolumn{2}{|c|}{ Annual Sales }} & 1 & $.347^{* *}$ & $.317^{* *}$ & 0.071 & $.289^{* *}$ & $.200^{*}$ \\
\hline & & & 0 & 0.001 & 0.484 & 0.003 & 0.046 \\
\hline \multirow{2}{*}{\multicolumn{2}{|c|}{ Reorder Point }} & & 1 & $.412^{* k}$ & $.397^{* *}$ & $.686^{* *}$ & $.358^{* *}$ \\
\hline & & & & 0 & 0 & 0 & 0 \\
\hline \multirow{2}{*}{\multicolumn{2}{|c|}{ Inventory Control }} & & & 1 & $.713^{* *}$ & $.891^{* *}$ & $.582^{* *}$ \\
\hline & & & & & 0 & 0 & 0 \\
\hline \multirow{2}{*}{\multicolumn{2}{|c|}{ Supplier }} & & & & 1 & $.875^{* *}$ & $.604^{* *}$ \\
\hline & & & & & & 0 & 0 \\
\hline \multirow{2}{*}{\multicolumn{2}{|c|}{ IMPs }} & & & & & 1 & $.637^{* *}$ \\
\hline & & & & & & & 0 \\
\hline Performar & & & & & & & 1 \\
\hline
\end{tabular}

\subsection{The mediating effects of knowledge of IMPs on IMPs and performance relationship}

The structural equation model using AMOS was performed to analyse the effect of IMPs on enterprise performance and the mediating role of inventory management knowledge on the relationship between IMPs and performance. The confirmatory factor analysis was conducted to ensure the appropriateness of the scales and that the measurement model constructs were in line with the literature. Table 5 presents the composite reliability (CR) coefficients for the constructs in the present model (IMP: Inventory Management Practice; EP: Enterprise Performance; and IK: Inventory Knowledge) are all greater than 0.70, suggesting that a high internal reliability in the constructs. Meanwhile, the average variance extracted (AVE) coefficients as shown in Table 5 are all larger than 0.5 , which suggests that the items are able to explain the variance in the constructs. Table 6 shows the results of discriminant validity. The diagonal values, in bold, is the square root of AVE of the three constructs while other values are the correlation between the respective constructs. The discriminant validity for all three constructs is achieved since the diagonal values are higher than the values in its respective matrices.

Table 5: Composite reliability coefficients

\begin{tabular}{|c|c|c|c|c|}
\hline Construct & Item & Factor Loading & $\mathrm{CR}$ & AVE \\
\hline \multirow[t]{3}{*}{ IMP } & Item1 & 0.49 & 0.781 & 0.556 \\
\hline & Item 2 & 0.86 & & \\
\hline & Item 3 & 0.83 & & \\
\hline \multirow[t]{3}{*}{$\mathrm{EP}$} & Item1 & 0.69 & & \\
\hline & Item 2 & 0.86 & 0.787 & 0.555 \\
\hline & Item 3 & 0.67 & & \\
\hline \multirow[t]{2}{*}{ IK } & Item1 & 0.92 & 0911 & 0837 \\
\hline & Item 2 & 0.91 & & \\
\hline
\end{tabular}

\begin{tabular}{cccc}
\multicolumn{4}{c}{ Table 6: Discriminant validity } \\
\hline & EP & IMP & IK \\
EP & $\mathbf{0 . 7 4 5}$ & & \\
IMP & 0.637 & $\mathbf{0 . 9 1 4}$ & \\
IK & 0.70 & 0.644 & $\mathbf{0 . 7 4 4}$ \\
\hline
\end{tabular}




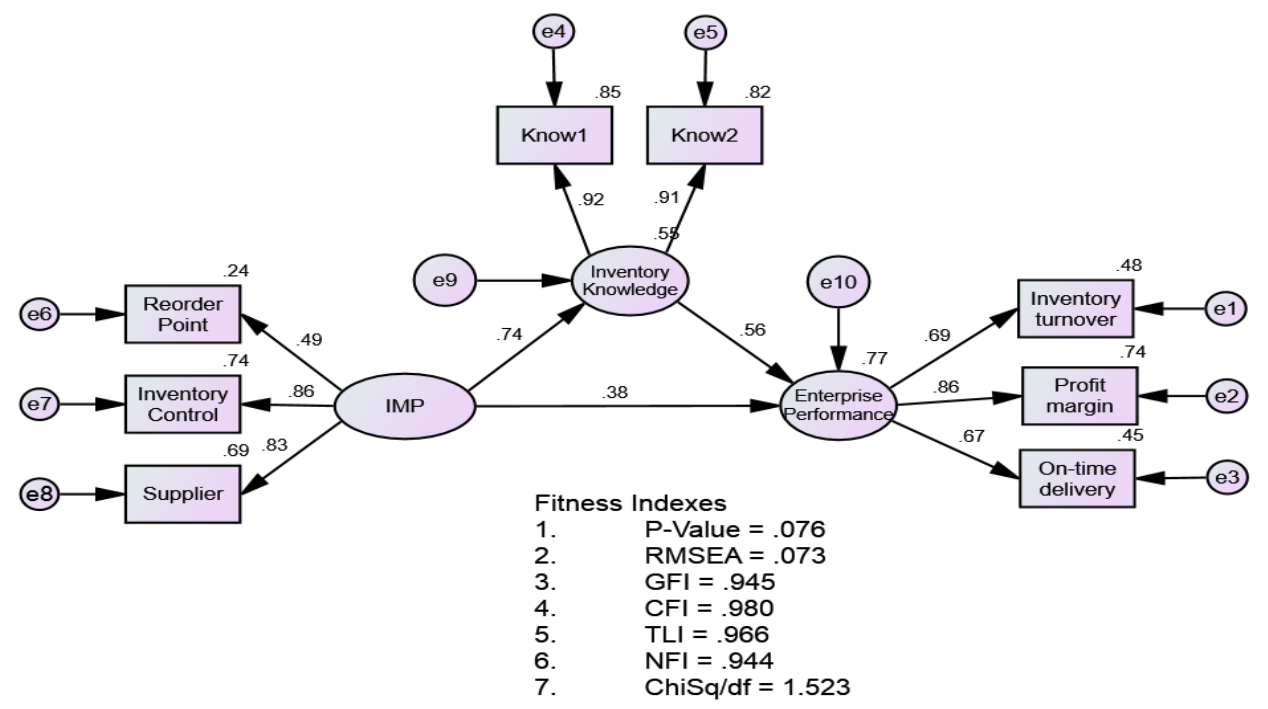

Figure 2: The standardised path coefficients between constructs

Figure 2 presents the model fit results based on absolute fit (RMSEA below than 0.08; GFI greater than 0.90), incremental fit (CFI; TLI; and NFI >0.9) and parsimonious fit (Chisq/ df < 3.0). Thus, all the model fitness requirements are achieved. The results in Figure 2 also shows the standardised path coefficients between the constructs that indicates the value of coefficient of determinant R-square was 0.77 . This suggests that the contribution of the exogenous variable in estimating the endogenous variable is $77 \%$. After the CFA analysis, the items for knowledge of inventory management are reduced to two items, and enterprise performance to three items. Next, the regression weight estimate for the model is presented in Figure 3 and the text output is in Table 8. Table 8 shows that the direct effect of IMP on enterprises performance is significant (beta coefficient: 1.721, p: 0.001). When the mediating variable (Knowledge) enters the model, the value of path coefficient for IMP is reduced to 0.754 . Based on the results, all hypotheses $\left(\mathrm{H}_{1}\right.$ to $\left.\mathrm{H}_{4}\right)$ are supported. Thus, the results suggest that there is partial mediation for our model where the IMP have a significant direct effect on enterprise performance and also a significant indirect effect on performance through knowledge of IMPs. Thus, our findings validate the hypothesised relations between IMPs and performance which is partially mediated by the knowledge of IMPs.

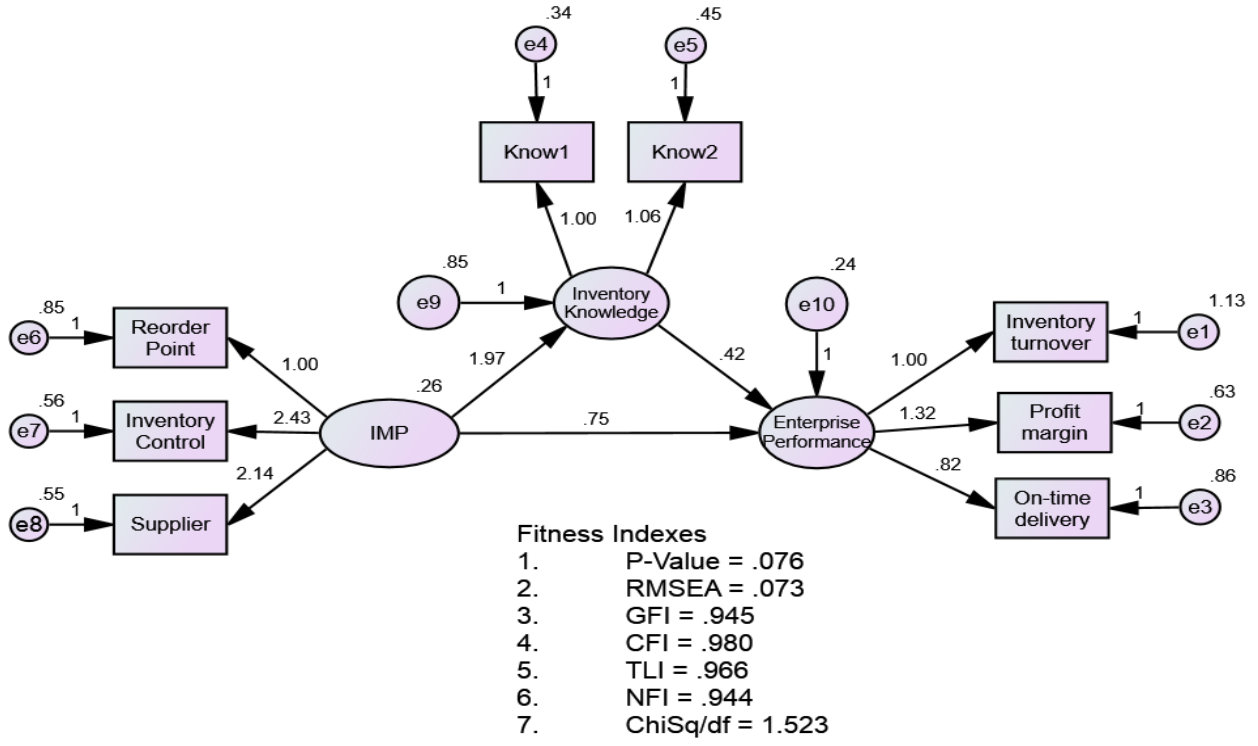

Figure 3: The unstandardised path coefficients between constructs 
Table 8: The regression weights and path coefficients

\begin{tabular}{|c|c|c|c|c|c|c|}
\hline \multicolumn{7}{|c|}{ Regression Weights: (Group number 1 - Default model) } \\
\hline \multicolumn{3}{|c|}{ The direct effect of IMP on performance } & Estimate & S.E. & C.R. & $\mathrm{P}$ \\
\hline \multicolumn{3}{|c|}{ Enterprise_Performance $<---\quad$ IMP } & 1.721 & 0.419 & 4.109 & $* * *$ \\
\hline \multicolumn{7}{|c|}{ The regression path coefficients and its significance based on $p$ value $<0.05$} \\
\hline Invontory Knowlodor & & & Estimate & S.E. & C.R. & $\mathrm{P}$ \\
\hline Inventory_Knowledge & $<---$ & IMP & 1.973 & 0.450 & 4.383 & *** \\
\hline Enterprise_Performance & $<---$ & Inventory Knowledge & 0.415 & 0.107 & 3.869 & *** \\
\hline Enterprise_Performance & $<--$ & IMP & 0.754 & 0.311 & 2.425 & .015 \\
\hline
\end{tabular}

\section{Conclusion}

This research reports the quantitative results obtained from 100 useable responses on questionnaires sent to 300 Malaysian micro enterprises in the retailing sector, enquiring about the mediating effect of inventory management knowledge on the relationship between inventory management practices and performance. Several conclusions can be drawn from this research. Firstly, most respondents have adopted a moderate level of systematic inventory design. Staffs own experience or rule of thumb appear to be the highest inventory management techniques which suggests the informal approach of inventory management. The responses seem sensible as small enterprises tend to make decisions based on their own judgement. The results are also reflected by the limitation of resources and expertise commonly faced by micro enterprises.

Furthermore, the analysis on the level of use of selected IMPs which are categorised into three categories (inventory reorder point, inventory control and supplier monitoring) suggests that the accuracy of information received from suppliers is seen as an important IMP procedure among responding enterprises. This is due to the critical role of suppliers through delivering inventories with accurate price and quantity information. Monitoring suppliers' performance through the evaluation on price, quality and quantity of materials and the reliability of the supplier is a fundamental part of ensuring continuity of sales since suppliers are in a position to ensure the continuity of supply of the required inventory. Watts et al. (1990) claimed that suppliers' competencies could significantly affect an organisation's ability to produce a quality product at a reasonable cost and in a timely manner. Having a list of valid and reliable suppliers as well as having a good relationship with suppliers is essential in ensuring the smooth flow of materials.

The correlation analysis demonstrates that IMPs is strongly and significantly related with performance which suggests that enterprises with a higher level of IMPs has more possibility to increase their performance. Additionally, the size of enterprises is significantly and positively associated with IMPs. Our results are consistent with previous arguments on the positive relationships between IMPs and performance and how the variation of IMPs associated with the size of enterprise. Finally, the findings indicate that there is partial mediating effect of knowledge of IMPs on IMPs-performance relationship. The IMPs have both significant direct effects on performance as well as indirect and significant effect on performance through knowledge of IMPs. The results support the previous arguments on the positive and significant link between IMPs and performance. For owners/managers of micro retailing enterprises, it is crucial to be aware of the need of qualified and knowledgeable staff in assuring effective inventory management.

This research has increased understanding of inventory management in a micro business setting. Pursuit of the benefits of improving inventory management places pressures in various areas of the production function. Organisations should make the decision on whether to incorporate one key inventory management technique or a combination of techniques to meet their needs to reach the maximum return. Waters (2003) emphasised that inventory management could be executed effectively by establishing an accurate sales forecast, inventory planning, building relationships with key suppliers, setting a realistic inventory turnover objective, determining the holding cost of inventory and providing sufficient training to key employees in understanding the inventory control system. In addition, Jonsson and Mattsson (2008) added that accurate lead times and safety stocks are two of the most critical factors 
for inventory system performance. Thus, micro enterprises should be equipped with proper knowledge in inventory management.

Overall, the results suggest that there is room for improvement in the micro enterprises' inventory management system. This work presents new additional evidence in IMPs and performance in micro retailing enterprises based on subjective measures. It highlights the importance of knowledge of IMPs in mediating IMPs towards improving the firm's performance. As such this study does not only contribute to the body of knowledge but also presents insightful findings on inventory management to the related policy makers particularly in improving micro enterprises growth and development in Malaysia. This study is limited to micro businesses in the retailing industry; thus, the findings are not generalised to other sectors or industries. Future studies should increase the number of samples in order to collect more reliable evidences in this area or add more contextual variables such as the effect of technologies, business strategies and culture on the application of IMPs within small businesses. It is also worthwhile to explore IMPs in other sectors as well, such as in the manufacturing or healthcare industries. Furthermore, in this study, subjective measures of the IMPs and performance were used. Further development of instruments in appraising the objective data relevant to IMPs and performance are needed to add more evidence in this area from a different quantitative approach.

\section{Reference}

Ayad, A 2008, 'Optimizing inventory and store results in big box retail environment' International Journal of Retail E Distribution Management, vol. 36, no. 3, pp. 180-191.

Ahmad, K \& Zabri, SM 2016, 'Inventory management practices among Malaysian micro retailing enterprises', Journal of Business and Retail Management Research, vol. 11, no.1, pp. 103-115.

Bahri, M, St-Pierre, J \& Sakka, O 2011, 'Economic value added: a useful tool for SME performance management', International Journal of Productivity and Performance Management, vol. 60, no.6, pp.603621

Bala, PK 2012, 'Improving inventory performance with clustering based demand forecasts', Journal of Modelling in Management, vol. 7, no.1, pp. 23-37.

Baron, O, Berman, O, \& Perry, D 2011, 'Shelf Space Management When Demand Depends on the Inventory Level', Production and Operations Management, vol. 20, no. 5, pp. 714-726.

Basu, N \& Wang, X 2011, 'Evidence on the relation between inventory changes, earnings and firm value', International Journal of Business and Finance Research, vol. 5, no.3, pp.1-14.

Boute, NR, Lambrecht, MRL, Lambrecht O \& Sterckx, P 2006, 'An analysis of inventory turnover in the Belgian manufacturing industry, wholesale and retail and the financial impact on inventory reduction', Faculty of Economics and Applied Economics.

Cannon, AR 2008, 'Inventory Improvement and Financial Performance', International Journal of Production Economics, vol.115, pp. 581-593

Chen, H, Frank, MZ \& Owen, QW 2005, 'What actually happened to the inventories of American companies between 1981 and 2005?', Management Science, vol. 51, no.7, pp. 1015-1031.

Chikan, A \& Whybark CD 1990, 'Cross-national comparison of production and inventory management practices', Engineering Costs and Production Economics, vol. 19, pp. 149-56.

Deloof, M 2003, 'Does working capital management affect profitability of Belgian firms?', Journal of Business Finance Accounting, vol. 30, no. 3-4, pp. 573-587.

Demeter, K 2003, 'Manufacturing strategy and competitiveness' International Journal of Production Economics, vol. 81/82, pp. 205-213.

De Vries, J 2011, 'The shaping of inventory systems in health services: A stakeholder analysis', International Journal of Production Economics, vol. 118, no. 1, pp. 136-145

Elsayed, K \& Wahba, H 2016, 'Reexamining the relationship between inventory management and firm performance: An organizational life cycle perspective', Future Business Journal, vol. 2, pp. 65-80.

Folinas, D \& Shen, CY 2014, 'Exploring Links among Inventory and Financial Performance in the Agricultural Machinery Industry', International Journal of Food and Agricultural Economics, vol. 2 no. 4, pp. 1-12. 
Fullerton, RK, McWatters, CS, \& Fawson, C 2003, 'An examination of the relationship between JIT and financial performance', Journal of Operations Management, vol. 21, no. 4, pp. 383-404.

Gaur, V \& Kesavan, S 2009, 'The effects of firm size and sales growth rate on inventory turnover performance in the US retail sector', Agrawal, N., Smith, (Eds.), Retail supply chain management: Quantitative models and empirical studies, Springer, US, pp. 25-52

García-Teruel, PJ \& Martínez-Solano, P 2007, 'Effects of working capital management on SME profitability', International Journal of Managerial Finance, vol. 3, no.2, pp.164-177,

Gitman, LJ \& Zutter, CJ 2012, ‘Principles of managerial finance. Boston: Pearson Prentice Hall

Heizer, J \& Render, B 2014, Operations Management, Sustainability and Supply Chain Management. 11th Ed. Pearson.

Jonsson, P \& Mattsson, SA 2008, 'Inventory management practices and their implications on perceived planning performance', International Journal of Production Research. vol. 46, no.7, pp. 1787-1812.

Keramidou, I, Mimis A \& Pappa, E 2011, 'Estimating technical and scale efficiency of meat products industry: The Greek case', Journal Applied Science, vol.11, no. 971-979.

Kinney, MR\& Wempe, WF 2002, 'Further evidence on the extent and origins of JIT's profitability effects', The Accounting Review, vol. 77, no.1, pp. 203-226.

Kolias, GD, Dimelis SP \& Filios, VP 2011, 'An empirical analysis of inventory turnover behaviour in Greek retail sector: 2000-2005', International Journal of Production Economics, vol. 133, no. 1, pp. 143-153.

Kotzab, H \& Teller, C 2005, 'Development and empirical test of grocery retail instore logistics model. British Food Journal, vol. 107, no. 8, pp. 594-605.

Koumanakos, DP 2008, 'The effect of inventory management on firm performance. International Journal of Productivity and Performance Management, vol. 57, no. 5, pp. 355-369.

Obermaier, R, \& Donhauser, A 2012, 'Zero inventory and firm performance: A management paradigm revisited', International Journal of Production Research, vol. 50, no.16, pp. 4543-4555.

Ogbo, AI, Onekanma IV, \& Wilfred IU 2014, 'The Impact of Effective Inventory Control Management on Organisational Performance: A Study of 7up Bottling Company Nile Mile Enugu, Nigeria', Mediterranean Journal of Social Sciences, vol. 5, no.10, pp. 109-118.

Panigrahi, AK 2013, 'Relationship between Inventory Management and Profitability: An Empirical Analysis of Indian Cement Companies', Asia Pacific Journal of Marketing \& Management Review, vol. 2, no. 7, pp. $107-120$.

Pong, C \& Mitchell F 2012, 'Inventory investment \& control: How have UK companies been doing?', British Accounting Review, vol. 44, no. 3, pp. 173-188.

Rajeev, N 2008, 'Inventory management in small and medium enterprises: A study of machine tool enterprises in Bangalore 'Management Research News, vol. 31, no.9, pp. 659-669.

Shah, R, \& Shin, H 2007, 'Relationships among information technology, inventory, and profitability: An investigation of level in variance using sector level data', Journal of Operations Management, vol. 25, no. 4, pp. 768-784.

Strohhecker, J \& Grobler, A 2013, ‘Do personal traits influence inventory management performance? The case of intelligence, personality, interest and knowledge', International Journal Production Economics, vol. 142, pp. 37-50.

Waller MA, Nachtmann, H \& Hunter, J 2006, 'Measuring the impact of inaccurate inventory information on a retail outlet', The International Journal of Logistics Management, vol. 17, no.3, pp. 355 -376.

Waters, D 2003, Inventory Control and Management, 2nd Edition, 1-408. Wiley.

Watts, CA, Kim, KY \& Hahn, CK 1990, 'The supplier development program: a conceptual model', Journal of Purchasing and Materials Management, pp. 2-7.

Vastag, G \& Whybark, DC 2005, 'Inventory management: is there a knock-on effect?', International Journal of Production Economics, vol. 93/94, no. 1, pp.129-138.

Zainudin, A 2015. SEM Made Simple: A Gentle Approach to Learning Structural Equation Modeling MPWS Publisher. Bangi Selangor. Malaysia 